\section{Detection of Proteolytic Activity by Fluorescent Zymogram In-Gel Assays}

BioTechniques 28:1166-1173 (June 2000)

\section{ABSTRACT}

Proteases are involved in the regulation of many biological functions. This study describes a novel method for detecting protease activity by fluorescent zymogram in-gel protease assays, using SDS polyacrylamide gels copolymerized with a peptideMCA (4-methyl-coumaryl-7-amide) substrate. This method allows simultaneous determination of protease cleavage specificity and molecular weight. Trypsin was electrophoresed in SDS polyacrylamide gels copolymerized with Boc-Gln-Ala-Arg-MCA, the gel was then incubated in assay buffer, and trypsin cleavage of the peptide-MCA substrate generated fluorescent AMC (7amino-4-methyl-coumarin), which was subsequently detected under UV transillumination. Chymotrypsin activity was detected in gels copolymerized with Suc-Ala-Ala-ProPhe-MCA substrate. Selective detection of these proteases was demonstrated by the absence of trypsin activity in gels containing the chymotrypsin substrate, and the lack of chymotrypsin activity in gels containing the trypsin substrate. Detection of proteolytic activity from secretory vesicles of adrenal medulla (chromaffin granules) was observed with the trypsin substrate, Z-PheArg-MCA, but not with the chymotrypsin substrate. Overall, this sensitive fluorescent zymogram in-gel protease assay method can be used for rapid determination of protease cleavage specificity and enzyme molecular weight in biological samples. This assay should be useful for many research disciplines investigating the role of the many proteases that control cellular functions.

\section{INTRODUCTION}

Proteases regulate key biological functions in health and disease. Limited proteolysis is involved in the control of cellular functions, including peptide hormone and neurotransmitter biosynthesis $(6,24,26)$, cell death $(23,28)$, transcriptional control of gene expres- sion $(22,31)$ and other functions. Aberrations in these proteolytic controls contribute to disease conditions such as cancer $(11,27)$, neurodegenerative diseases $(3,5,21)$ and viral infections $(9,25)$. Investigations of proteases require informative and sensitive assays to optimize their characterization. In this report, a novel method is described for the detection of proteolytic activity by sensitive, fluorescent zymogram in-gel protease assays that provide information about protease cleavage specificity and molecular weight. This method differs from previously reported zymogram protease assays $(8,12,16,18,19)$.

Proteases typically possess specificity for cleavage at particular amino acid residues. The $\mathrm{P} 1$ residue at the $\mathrm{N}$ terminal side of the cleaved peptide bond (cleavage between P1-P1' residues) is an important determinant of protease cleavage specificity (2). Based on this selectivity, fluorogenic peptideMCA (4-methyl-coumaryl-7-amide) substrates are widely used to detect proteolytic activity $(1,4,10)$. Cleavage between the $\mathrm{X}-\mathrm{MCA}(\mathrm{X}=\mathrm{P} 1$ residue $)$ bond of a peptide-MCA substrate liberates AMC (7-amino-4-methyl-coumarin), which is detected fluorometrically.

Using peptide-MCA substrates copolymerized into SDS polyacrylamide gels, we have developed a fluorescent in-gel protease assay that allows direct evaluation of proteolytic activity in the gel in situ to acquire information about protease cleavage specificity and molecular weight. This method has the advantage that it is nonradioactive and allows detection of low levels of enzyme activity. The fluorescent zymogram in-gel protease assay with peptide-MCA substrates allows direct determination of protease activity to simultaneously gain information about protease cleavage specificity and apparent molecular weights of proteases in biological samples.

\section{MATERIALS AND METHODS}

In-gel trypsin assays used SDS polyacrylamide gels copolymerized with the trypsin substrate Boc-Gln-AlaArg-MCA prepared by the method of Laemmli (15). All solutions were sterilized by filtration through $0.22-\mu \mathrm{m}$ membranes (Millipore, Bedford, MA, USA) and boiled before use. The resolving gel consisted of $200 \mu \mathrm{M}$ BocGln-Ala-Arg-MCA (Bachem California, Torrance, CA, USA), $14 \%$ polyacrylamide, $0.37 \%$ bis-acrylamide, $0.375 \mathrm{M}$ Tris- $\mathrm{HCl}(\mathrm{pH} 8.8)$ and $0.1 \%$ SDS cast in a Novex gel cassette (Invitrogen, Carlsbad, CA, USA) with gel dimensions of $8 \times 7 \times 0.1 \mathrm{~cm}$. Polymerization of polyacrylamide was conducted in the dark at room temperature for 1 h. The $6 \%$ polyacrylamide stacking gel contained $0.25 \mathrm{M}$ Tris- $\mathrm{HCl}(\mathrm{pH} 6.8)$ and $0.03 \%$ SDS; the gel was allowed to polymerize for $1 \mathrm{~h}$ at room temperature. Trypsin (0.5-100 ng, Roche Molecular Biochemicals, Indianapolis, IN, USA) was prepared in $1 \times$ sample buffer [50 mM Tris- $\mathrm{HCl}$ (pH 6.8), 0.1\% SDS and $2 \%$ glycerol] and was subjected to electrophoresis with $1 \times$ running buffer [25 mM Tris-HCl (pH 8.3), $192 \mathrm{mM}$ glycine and $0.1 \% \mathrm{SDS}]$ at $4^{\circ} \mathrm{C}$ for $1 \mathrm{~h}$ at a constant current of $25 \mathrm{~mA}$. The gel was then washed in cold $2.5 \%$ Triton $^{\circledR}$ X-100 solution for $10 \mathrm{~min}$, and in cold distilled water for $10 \mathrm{~min}$. The gel was incubated in trypsin assay buffer [50 $\mathrm{mM}$ Tris- $\mathrm{HCl}(\mathrm{pH} 7.5), 10 \mathrm{mM} \mathrm{CaCl}_{2}$ and $0.005 \%$ Triton $\mathrm{X}-100$ ) at $37^{\circ} \mathrm{C}$ for $30 \mathrm{~min}$. For in-solution gel assays of trypsin, Boc-Gln-Ala-Arg-MCA was omitted from the gel, and after electrophoresis, gels were incubated in trypsin assay buffer containing $200 \mu \mathrm{M}$ Boc-Gln-Ala-Arg-MCA. Fluorescent bands of trypsin activity were immediately observed by a Model TFX 35M UV-B transilluminator (Bio-Rad Laboratories, Hercules, CA, USA) $(385 \mathrm{~nm}$ $=$ AMC group excitation wavelength). Fluorescent images were recorded by the Kodak ${ }^{\circledR}$ DC120 digital camera and were analyzed by the Kodak Electrophoresis Documentation and Analysis System (EDAS) 120 (Eastman Kodak, Rochester, NY, USA).

It was noted that detection of proteolytic activity in fluorogenic peptideMCA zymogram gels was optimized when zymogram gels were prepared on the same day as electrophoresis and assay. In addition, diffusion of the AMC fluorescent group is minimal with these short incubation times and immediate detection of fluorescence.

Chymotrypsin (Worthington Biochemical, Lakewood, NJ, USA) activi- 


\section{Short Technical Reports}

ty was assessed by in-gel assay in a $14 \%$ polyacrylamide gel with $200 \mu \mathrm{M}$ Suc-Ala-Ala-Pro-Phe-MCA (Bachem California) copolymerized in the resolving gel, with a stacking gel of $6 \%$ polyacrylamide. Electrophoresis was performed and the gel treated under the same conditions as described above. The assay buffer used for chymotrypsin activity contained $50 \mathrm{mM}$ Tris- $\mathrm{HCl}(\mathrm{pH}$ 7.5) and $0.005 \%$ Triton $\mathrm{X}-100$. The gel was incubated at $37^{\circ} \mathrm{C}$ for $30 \mathrm{~min}$. Activity bands were observed under a UV

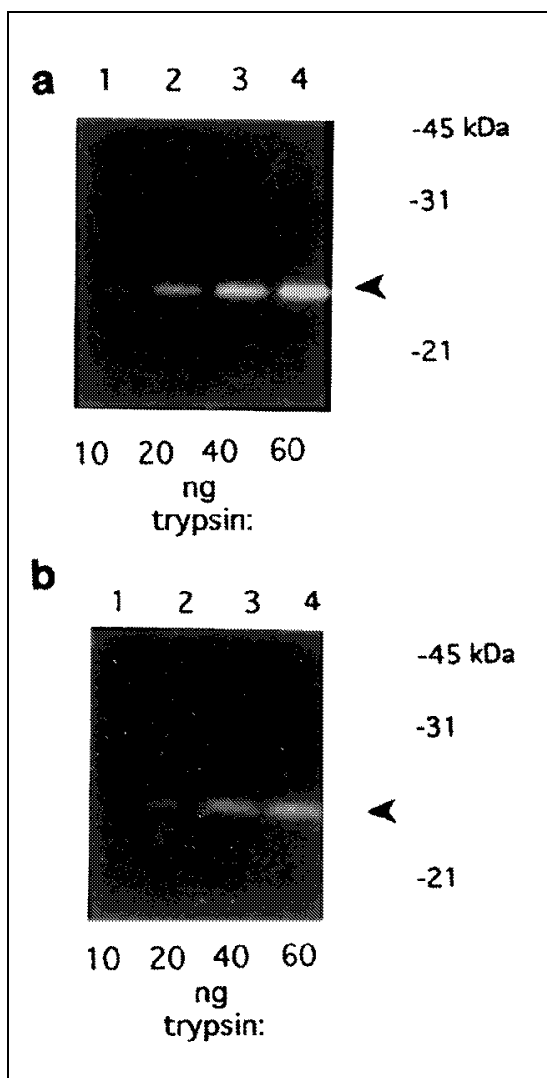

Figure 1. Fluorescent in-gel zymogram assay of trypsin. (a) In-gel assay of trypsin with gels containing peptide-MCA substrate. Various amounts of trypsin (10, 20, 40 and $60 \mathrm{ng}$ in lanes $1-4$, respectively) were subjected to electrophoresis on a SDS polyacrylamide gel (14\% polyacrylamide) copolymerized with $200 \mu \mathrm{M}$ Boc-Gln-Ala-Arg-MCA substrate. After incubating the gel in assay buffer at $37^{\circ} \mathrm{C}$ for $30 \mathrm{~min}$, trypsin activity was detected as a fluorescent 25 kDa band (arrow). (b) Assay of trypsin with peptide-MCA substrate in the in-solution assay. Known amounts of trypsin (10, 20, 40 and $60 \mathrm{ng}$ in lanes 1-4, respectively) were subjected to SDS-PAGE without substrate in the gel. The gel was then incubated in assay buffer containing 200 $\mu \mathrm{M}$ Boc-Gln-Ala-Arg-MCA substrate at $37^{\circ} \mathrm{C}$ for $30 \mathrm{~min}$. Trypsin activity was detected as a 25 $\mathrm{kDa}$ fluorescent band (arrow). transilluminator and documented as described for trypsin.

To demonstrate the specificity of the in-gel fluorescent zymogram technique for detection of proteases, we compared the activities of trypsin and chymotrypsin, as well as a biological sample of isolated secretory vesicles from adrenal medulla (chromaffin granules) in gels copolymerized with three different peptide-MCA substrates $(200 \mu \mathrm{M}$ each). Chromaffin granules were prepared as described previously $(14,30)$. Different amounts of trypsin, chymotrypsin and chromaffin granules (lysed) were electrophoresed in gels containing Boc-Gln-Ala-Arg-MCA (trypsin substrate), Suc-Ala-Ala-ProPhe-MCA (chymotrypsin substrate) or Z-Phe-Arg-MCA (trypsin substrate). The Boc-Gln-Ala-Arg-MCA gel was incubated in $50 \mathrm{mM}$ Tris- $\mathrm{HCl}(\mathrm{pH} 7.5)$, $10 \mathrm{mM} \mathrm{CaCl}_{2}$ and $0.005 \%$ Triton $\mathrm{X}$ 100; the Suc-Ala-Ala-Pro-Phe-MCA was incubated in $50 \mathrm{mM}$ Tris- $\mathrm{HCl}(\mathrm{pH}$ 7.5 ) and $0.005 \%$ Triton $\mathrm{X}-100$; and the Z-Phe-Arg-MCA gel was incubated in $100 \mathrm{mM}$ citric acid (pH 5.0), $1 \mathrm{mM}$ EDTA, $1 \mathrm{mM}$ DTT and $10 \mathrm{mM}$ CHAPS for $30 \mathrm{~min}$ at $37^{\circ} \mathrm{C}$.

To detect molecular weight markers (BenchMark protein ladder; Life Technologies, Rockville, MD, USA) on gels

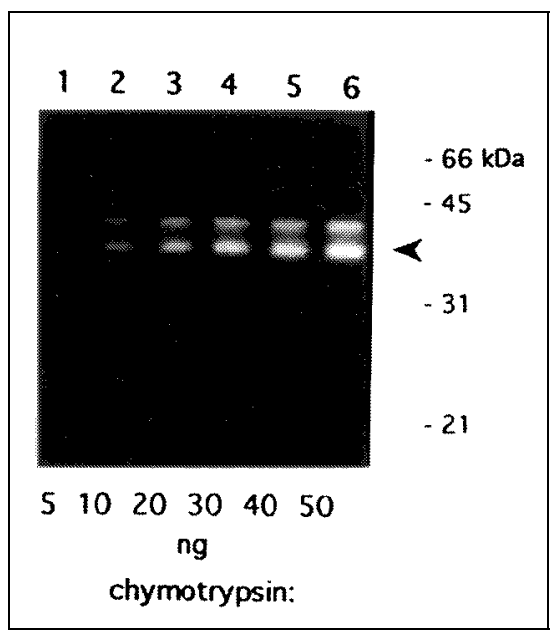

Figure 2. Fluorescent in-gel zymogram assay of chymotrypsin. Various amounts of chymotrypsin $(5,10,20,30,40$ and $50 \mathrm{ng}$ in lanes $1-6$, respectively) were electrophoresed on a $14 \%$ SDS polyacrylamide gel with $200 \mu \mathrm{M}$ Suc-AlaAla-Pro-Phe-MCA copolymerized in the gel. The gel was incubated in chymotrypsin assay buffer for $30 \mathrm{~min}$ at $37^{\circ} \mathrm{C}$. Chymotrypsin activity was detected as two fluorescent bands (arrow). after fluorescent in-gel protease assays were conducted, gels were stained for protein in $0.2 \%$ (w/v) Coomassie Brilliant Blue R-250 ${ }^{\circledR}$ (Bio-Rad Laboratories), $50 \%$ methanol and $7 \%$ acetic acid; gels were then destained in $50 \%$ methanol and $7 \%$ acetic acid. Gels were soaked in Gel-Dry ${ }^{\mathrm{TM}}$ drying solution for $30 \mathrm{~min}$ at room temperature and air-dried using the DryEase ${ }^{\circledR}$ MiniGel drying system (both from Invitrogen). Images of the Coomassie-stained gels were recorded and analyzed by the Kodak digital camera and EDAS.

\section{RESULTS}

Trypsin activity was detected by the fluorescent zymogram in-gel protease assay method with Boc-Gln-Ala-ArgMCA substrate copolymerized in the SDS polyacrylamide gel (Figure 1). Various amounts of trypsin $(10,20,40$ and $60 \mathrm{ng}$ ) were subjected to electrophoresis followed by incubation in 


\section{Short Technical Reports}

assay buffer at $37^{\circ} \mathrm{C}$ for $30 \mathrm{~min}$. Fluorescent bands representing trypsin activity that cleaved at the Arg-MCA bond of Boc-GIn-Ala-Arg-MCA to liberate fluorescent $\mathrm{AMC}$ was detected using UV transillumination (Figure 1a). This sensitive fluorescent in-gel substrate assay detected nanogram levels (20 ng) of $25-\mathrm{kDa}$ trypsin, which is consistent with its known molecular weight. Moreover, trypsin activity bands were sharp and highly defined.

For comparison, fluorescent in-solution gel assays of trypsin were performed by electrophoresis on SDS polyacrylamide gels without peptide-MCA substrate, followed by incubation of gels in assay buffer containing Boc-Gln-AlaArg-MCA at $37^{\circ} \mathrm{C}$ for $30 \mathrm{~min}$ (Figure 1b). Detection of trypsin by the in-solution assay required higher levels of trypsin (at least $40 \mathrm{ng}$ ) than the in-gel method. In addition, the fluorescence activity band was more diffuse in the insolution assay. These results demonstrate that the in-gel assay format with
peptide-MCA substrate copolymerized in the gel is more sensitive than the insolution assay method. Copolymerization of peptide-MCA substrate in SDS polyacrylamide gels for zymogram protease assays represents a novel approach for identifying proteolytic activities.

To further assess the detection of proteases by the fluorescent in-gel zymogram assay, the detection of chymotrypsin in gels containing the chymotrypsin substrate Suc-Ala-Ala-ProPhe-MCA was tested (Figure 2). Sensitive detection of chymotrypsin activity was achieved, as demonstrated by the production of fluorescent bands of activity with as low as $10 \mathrm{ng}$ chymotrypsin. Under the conditions of these nonreducing gels, a primary $37-38 \mathrm{kDa}$ band of chymotrypsin activity was detected, as well as an activity band of 41-42 kDa. Chymotrypsin possesses two pairs of disulfide bonds that may influence the electrophoretic mobility of the enzyme under nonreducing con-

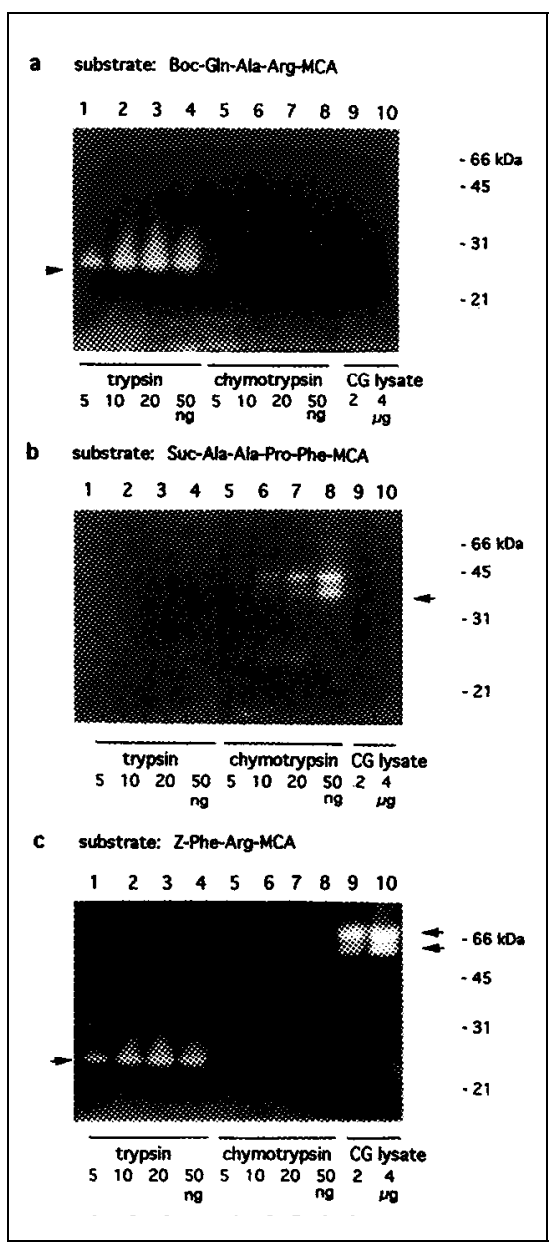

ditions (29). Under reducing conditions, chymotrypsin possesses an apparent molecular weight of $25 \mathrm{kDa}(7)$. These results demonstrate the sensitive detection of both chymotrypsin and trypsin by peptide-fluorescent substrates copolymerized in the in-gel zymogram assay.

The selective detection of trypsin and chymotrypsin based on their different cleavage specificities was assessed. Trypsin but not chymotrypsin was detected in gels containing the trypsin substrate Boc-Gln-Ala-Arg-MCA (Figure 3a). Furthermore, chymotrypsin but not trypsin was detected in gels containing the chymotrypsin substrate SucAla-Ala-Pro-Phe-MCA (Figure 3b). These results demonstrate that distinct proteases may be selectively detected by different peptide-MCA substrates.

Proteolytic activity in a biological sample by the fluorescent in-gel assay was demonstrated in this study. Isolated chromatin granules from bovine adrenal medulla contained proteolytic activities of 70 and $60 \mathrm{kDa}$ that were detected using Z-Phe-Arg-MCA, a substrate for trypsin (Figure 3c). However, proteolytic activities from these granules were not detected using a different trypsin substrate, Boc-Gln-Ala-Arg-MCA (Figure $3 a$ ). Furthermore, the granule activity was not detected using the chymotrypsin substrate Suc-Ala-Ala-Pro-Phe-

Figure 3. Substrate specificity of in-gel zymogram assays to detect different proteases. (a) Boc-Gln-Ala-Arg-MCA zymogram in-gel assay: detection of trypsin but not chymotrypsin or chromaffin granule proteolytic activities. Various amounts of trypsin $(5,10,20$ and $50 \mathrm{ng}$ in lanes $1-4$, respectively), chymotrypsin $(5,10,20$ and $50 \mathrm{ng}$ in lanes 5-8, respectively) and lysed chromaffin granules ( 2 and $4 \mu \mathrm{g}$ in lanes 9 and 10, respectively) were subjected to electrophoresis under nonreducing conditions on a $14 \%$ polyacrylamide gel copolymerized with Boc-GlnAla-Arg-MCA. Gels were assayed for proteolytic activities as described in Materials and Methods. Fluorescent bands of proteolytic activity are indicated (arrow). (b) Suc-Ala-Ala-Pro-Phe-MCA zymogram in-gel assay: detection of chymotrypsin but not trypsin or chromaffin granule proteolytic activities as in (a) but with Suc-Ala-AlaPro-Phe-MCA copolymerized in the gel. Fluorescent bands of proteolytic activity are indicated (arrow). (c) Z-Phe-Arg-MCA zymogram in-gel assay: detection of trypsin and chromaffin granule proteolytic activities but not chymotrypsin as in (a) but with Z-Phe-Arg-MCA copolymerized in the gel. Fluorescent bands of proteolytic activities are indicated (arrows). 


\section{Short Technical Reports}

MCA. These findings demonstrate that cleavage site-specific proteases can be characterized by the choice of peptideMCA substrate copolymerized in the fluorescent zymogram gels.

\section{DISCUSSION}

This report demonstrates the simple and sensitive method of fluorescent zymogram in-gel protease assays that provides information about the protease's cleavage specificity and molecular weight. Multiple fluorogenic peptideMCA substrates can be used to simultaneously assess protease cleavage specificities and their apparent molecular weights. This assay can be used to selectively detect a protease in a biological sample that recognizes and cleaves a specific peptide sequence, in the form of a peptide-MCA substrate. Moreover, this in-gel protease assay may be useful for identifying several proteases of different molecular weights present in a single sample.

Several previous reports $(13,17,20)$ demonstrate the detection of protease activity after electrophoresis in nonreducing gels by electrophoretic transfer of proteases to nitrocellulose membranes, followed by the incubation of the membrane with peptide-p-nitroanilide substrates to detect activity. The advantages of the fluorescent in-gel assays discussed in this study over the previous methods are: (i) gels copolymerized with peptide-MCA substrate will assay a greater proportion of the protease compared to transfer of the protease to nitrocellulose membranes because only a fraction of the total protein in the gel is electrophoretically transferred; (ii) gels containing peptideMCA substrate are more sensitive than the incubation of nitrocellulose membranes in an assay solution containing
peptide-pNA substrates because picomolar levels of AMC can be detected compared to $p$-nitroaniline (nanomolar levels detected); and (iii) gels containing peptide-MCA substrates provide a more direct and rapid procedure for detection of proteolytic activity.

The fluorescent in-gel method is also advantageous compared with a commercially available enzyme overlay membrane method that detects protease activity by overlaying the gel with a peptide-MCA-containing membrane that only assays the enzymes at the gelmembrane interface. However, the ingel method in this study assays the entire enzyme sample contained in the gel colpolymerized with substrate.

The determination of the mechanistic class of the protease may also be conducted by including protease inhibitors in the assay buffer during incubation of the gel to monitor proteolytic activity (30). This assay should be use- 
ful for many research disciplines investigating the role of the numerous proteases that control biological functions.

\section{REFERENCES}

1.Azaryan, A.V. and V.Y.H. Hook. 1994 Unique cleavage specificity of 'prohormone thiol protease' related to proenkephalin processing. FEBS Lett. 341:197-202.

2.Benyon, R.J. and J.S. Bond. 1989. The schecter and berger nomenclature for protease subsites, p. 231. In R.J. Beynon and J.S. Bond (Eds.), Proteolytic Enzymes: A Practical Approach. Oxford University Press, Oxford.

3.Citron, M., T.S. Diehl, G. Gordon, A.L. Biere, P. Seubert, D.J. Selkoe. 1996. Evidence that the 42- and 40-amino acid forms of amyloid beta protein are generated from the betaamyloid precursor protein by different protease activities. Proc. Natl. Acad. Sci. USA 93: 13170-13175.

4.Denmeade, S.R., W. Lou, J. Lovgren, J. Malm, H. Lilja and J.T. Isaacs. 1997. Specific and efficient peptide substrates for assaying the proteolytic activity of prostate-specific antigen. Cancer Res. 57:4924-4930.

5.Goldberg, Y.P., D.W. Nicholson, D.M. Rasper, M.A. Kalchman, H.B. Koide, R.K. Graham, M. Bromm, P. Kazemi-Esfarjani et al. 1996. Cleavage of huntingtin by apopain, a proapoptotic cysteine protease, is modulated by the polyglutamine tract. Nat. Genet. 13:442449.

6.Hook, V.Y.H. 1998. Proteolytic and Cellular Mechanisms in Prohormone and Proprotein processing, p. 1-204. R.G. Landes Co., Austin, TX.

7.Hook, V.Y.H., R.T. Purviance, A.V. Aza.ryan, G. Hubbard and T.K. Krieger. 1993. Purification and characterization of $\alpha_{1}$-antichymotrypsin-like protease inhibitor that regulates 'prohormone thiol protease' (PTP) involved in enkephalin precursor processing. J. Biol. Chem. 268:20570-20577.

8.Irvine, J.W., S.F. Roberts and I. Lindberg. 1990. Electrophoretic analysis of proteinases in sodium dodecyl sulfate-polyacrylamide gels containing copolymerized radiolabeled protein substrates: application to proenkephalin processing enzymes. Anal. Biochem. 190:141146.

9.Kaul, D.R., S.K. Cinti, P.L. Carver and P.H. Kazanjian. 1999. HIV protease inhibitors: advances in therapy and adverse reactions, including metabolic complications. Pharmacotherapy 19:281-298.

10.Kawabata, S.I., T. Miura, T. Morita, H. Kato, K. Fujikawa, S. Iwanaga, K. Takada, T. Kimura and S. Sakakibara. 1988. Highly sensitive peptide-4-methylcoumaryl-7-amide substrates for blood-clotting proteases and trypsin. Eur. J. Biochem. 172:17-25.

11.Keppler, D. and B.F. Sloane. 1996. Cathepsin B: multiple enzyme forms from a single gene and their relation to cancer. Enzyme Protein 49:94-105.

12.Kleiner, D.E. and W.G. Stetler-Stevenson. 1994. Quantitative zymography: detection of picogram quantities of gelatinases. Anal. Bio- chem. 218:325-329.

13.Koivunen, E. 1989. Detection of trypsin- and chymotrypsin-like proteases using p- nitroanilide substrates after sodium dodecyl sulphate polyacrylamide gel electrophoresis. J. Chromatogr. 470:401-406.

14.Krieger, T.J. and V.Y.H. Hook. 1991. Purification and characterization of a novel thiol protease involved in processing of the enkephalin precursor. J. Biol. Chem. 266:8376-8383.

15.Laemmli, U.K. 1970. Cleavage of structural proteins during the assembly of the head bacteriophage T4. Nature 227:680-685.

16.Leber, T.M. and F.R. Balkwill. 1997. Zymography: a single step method for quantitation of proteolytic activity on substrate gels. Anal. Biochem. 249:24-28.

17.Manchenko, G. 1994. Handbook of Detection of Enzymes in Electrophoretic Gels. p. 261262. CRC Press, Boca Raton, FL.

18.Oliver, G.W., J.D. Leferson, W.G. StetlerStevenson and D.E. Kleiner. 1997. Quantitative reverse zymography: analysis of picogram amounts of metalloproteinase inhibitors using gelatinase A and B reverse zymograms. Anal. Biochem. 244:161-166.

19.Peach, C., T. Christianson and K.-H. Maurer. 1993. Zymogram of proteases made with developed film from nondenaturing polyacrylamide gels after electrophoresis. Anal. Biochem. 208:249-254.

20.Pederson, E.D. and B.L. Lamberts. 1990 Detection of microbiol trypsin-like enzymes by use of an agar gel. Microbios 63:165-171.

21.Price, D.L., R.E. Tanzi, D.R. Borchelt and S.S. Sisodia. 1998. Alzheimer's disease: genetic studies and transgenic models. Ann. Rev. Genetics 32:461-493.

22.Sakai, J., R.B. Rawson, P.J. Espenshade, D. Cheng, A.C. Seegmiller, J.L. Goldstein and M.S. Brown. 1998. Molecular identification of the sterol-regulated luminal protease that cleaves SREBPs and controls lipid composition of animal cells. Mol. Cell 2:505-514.

23.Schulz, J.B., M. Weller and M.A. Moskowitz. 1999. Caspases as treatment targets in stroke and neurodegenerative diseases. Annal. Neurol. 45:421-429.

24.Seidah, N.G., R. Day and M. Chretien. 1994. The family of subtilisin kexin-like proprotein convertases: divergent or shared functions. Biochimie 76:197-209.

25.Seybert, A., J. Ziebuhr and S.G. Siddell. 1997. Expression and characterization of a recombinant murine coronavirus $3 \mathrm{C}$-like proteinase. J. Gen. Virol. 78:71-75.

26.Steiner, D.F., S.P. Smeekens, S. Ohagi and S.J. Chan. 1992. The new enzymology of precursor processing of endoproteases. J. Biol. Chem. 267:23435-23438.

27.Tanimoto, H., L.J. Underwood, K. Shigemasa, T.H. Parmley, Y. Wang, Y. Yan, J. Clarke and T.J. O'Brien. 1999. The matrix metalloprotease pump-1 (MMP-7, matrilysin): a candidate marker/target for ovarian cancer detection and treatment. Tumour Biol. 20:88-98.

28.Thornberry, N.A. and Y. Lazebnik. 1998. Caspases: enemies within. Science 281:13121316.

29.Voet, D. and J.G. Voet. 1990. Biochemistry, p. 382-383. John Wiley \& Sons, New York.

30. Yasothornsrikul, S., W. Aaron, T. Toneff and
V.Y.H. Hook. 1999. Evidence for the proenkephalin processing enzyme prohormone thiol protease (PTP) as a multicatalytic cysteine protease complex: activation by glutathione localized to secretory vesicles. Biochem. 38:74217430.

31.Zhang, Y., Z. Wang, D.X. Liu, M. Pagano and K. Ravid. 1998. Ubiquitin-dependent degradation of cyclin B is accelerated in polyploid megakaryocytes. J. Biol. Chem. 273: 1387-1392.

This work was supported by National Institutes of Health grant nos. DA04271, NS24553 and DA08825 to V.H. Address correspondence to Dr. Vivian Hook, Department of Medicine, University of California, San Diego, 9500 Gilman Dr. \#0822, La Jolla, CA 92093-0822, USA. Internet: vhook@ucsd.edu

Received 10 June 1999; accepted 22 February 2000.

Sukkid Yasothornsrikul and

Vivian Y.H. Hook

University of California

San Diego

La Jolla, CA, USA 